\title{
A COMPARATIVE ANALYTICAL AND EXPERIMENTAL ANALYSIS OF SLOSHING WAVES IN RECTANGULAR TANK UNDER SEISMIC CONDITION
}

\author{
Dushyant Kumar Sahu ${ }^{1}$, Hina Gupta ${ }^{2}$, Nirendra $\operatorname{Dev}^{3}$, Alok Verma ${ }^{4}$ \\ ${ }^{1}$ Assistant Professor, ABES Engineering College, Ghaziabad-201009, India \\ dushyant.sahu1990@gmail.com \\ ${ }^{2}$ Scientist, CSIR-Central Building Research Institute, Roorkee-247667, India \\ 15hinagupta@gmail.com \\ ${ }^{3}$ Professor, Delhi Technological University, Delhi-110042, India \\ nirendra61@gmail.com \\ ${ }^{4}$ Associate Professor, Delhi Technological University, Delhi-110042, India \\ alokverma_dce@hotmail.com
}

\begin{abstract}
Many past earthquakes have witnessed failure of liquid storage tanks in various ways. Sloshing action is one of major kinds of them. Hence it becomes essential to detect the pattern of surface wave and use preventive measures. As we know that the mass of water can be thought of as two parts, impulsive at lower depth and convective at upper depth. This analysis work was primarily focused on convective part. In this experimental study, the earthquake induced waves were analyzed with a representing tank model using shake table facility at DTU, Delhi. Further, the wave patterns and seismic parameters were determined analytically, and results were compared. The work gives a fair idea to study the seismic behavior of liquid storage tanks.
\end{abstract}

Keywords: Rectangular Water Tank, Sloshing Waves, Shake Table, Natural Frequency, Fluid-Structure Interaction.

\section{INTRODUCTION}

Liquid storage tank is a very important structure to serve normally and even after the disasters like earthquake, fire, etc. Hence it becomes an important structure. At the time of earthquake the container experiences huge hydrodynamic pressure. Thus the understanding of behavior and nature of these pressures becomes more important for the safe design. A lot of works have been carried out to analyze seismically the liquid storage tanks by approaches like finite element techniques[1], computational procedure[2], endurance time method[3], etc. and other traditional approaches which we use for design. All these techniques need the idea about behavior of earthquake induced waves, their natural frequencies, wave patterns, etc.

Tanks that have not designed or detailed adequately may suffer serious damages during earthquake. The various seismic damage modes in liquid storage tanks are buckling of side walls (diamond buckling), failure of tank roof and their junction, failure of anchor bolts, sliding and lifting, elephant foot buckling of tank wall at bottom, and uneven settlement, etc. [4][5]. Most of these failure modes are largely affected by sloshing of liquid and wave induced at the free surface. To safeguard against these, a good idea of sloshing height and sloshing load is required [6], so that we can provide sufficient freeboard or strength to prevent these damages economically.

In this experimental work a model of water tank was used which represents a rigid walled rectangular tank with fixed base over the ground. It was simulated on shake table to study the behavior of earthquake induced waves.

\section{FLUID-STRUCTURE INTERACTION}

The structure of liquid storage tank is rigid and elastic where as liquid containing in it is fluid and plastic or viscous in nature. When a dynamic force is applied on it, interaction between them takes place making the analysis more difficult. There are many approached to investigate the problem, as discussed in literatures of [7]-[9]. Out of all them the model suggested by Housner[10] was earliest and most accepted by the codes. According to Housner mass of liquid inside the tank can be thought of as two parts, one impulsive $\left(\mathrm{m}_{\mathrm{i}}\right)$ at the lower part which behaves as rigidly connected with the tank walls and another convective at upper part which oscillates horizontally against a restraining spring. Its mechanical spring-mass model is shown in Fig.1.

\section{WAVE PATTERN IN RECTANGULAR TANK}

Rectangular tank will have length and width on the plan. Considering the excitation force to be acting along the length, thus its 2-D model is shown in Fig.1(a). The model has length $2 l$ (or $L$ ) and depth of water $h$ with coordinate axes as shown in the figure. As most of these waves are irrotational [11], thus assuming inviscid and incompressible fluid we can write following differential equation and boundary conditions. 


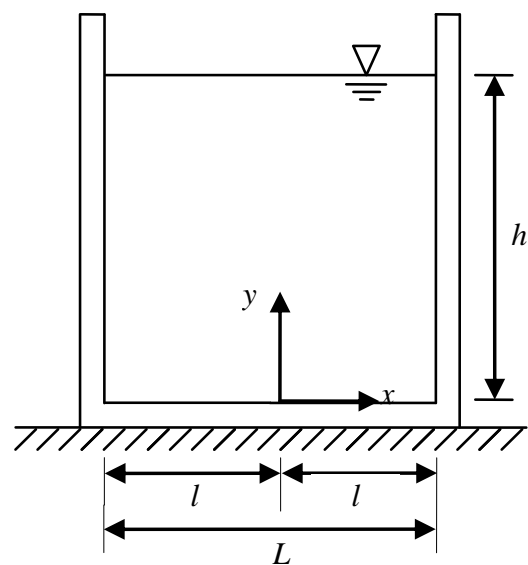

(a) Tank

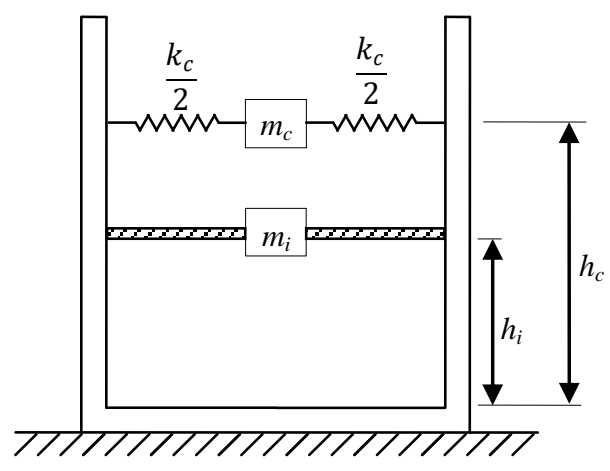

(b) Spring-Mass Model

Fig.1- Housner's Model

$\frac{\partial^{2} \phi}{\partial x^{2}}+\frac{\partial^{2} \phi}{\partial y^{2}}=0$

$\frac{\partial^{2} \phi}{\partial t^{2}}(x, h, t)+g \frac{\partial \phi}{\partial y}(x, h, t)=0$

$\frac{\partial \phi}{\partial y}(x, 0, t)=0$

$\frac{\partial \phi}{\partial x}( \pm l, y, t)=0$

Where, $\phi(x, y, t)$ represents velocity potential, $g$ acceleration due to gravity, and $t$ time. Boundary condition (2) is derived from Bernoulli's equation using at free surface. Rest other two boundary conditions (3) and (4) are based on dimensions of tank. After some time of disturbance the wave will attain steady state condition. Thus, we can write velocity potential as, $\phi(x, y, t)=\psi(x, y) \cos \omega t$ and above equations will be modified as,

$\frac{\partial^{2} \psi}{\partial x^{2}}+\frac{\partial^{2} \psi}{\partial y^{2}}=0$

$-\omega^{2} \psi(x, h)+g \frac{\partial \psi}{\partial y}(x, h)=0$

$\frac{\partial \psi}{\partial y}(x, 0)=0$

$\frac{\partial \psi}{\partial x}( \pm l, y)=0$

Solution of $\psi(x, y)$ in variable separable form will be, $X(x) Y(y)$. Thus, from (5)

$\frac{d^{2} X}{d x^{2}} Y+X \frac{d^{2} Y}{d y^{2}}=0$

$\Rightarrow \frac{1}{X} \frac{d^{2} X}{d x^{2}}=-\frac{1}{Y} \frac{d^{2} Y}{d y^{2}}=-\lambda^{2}$ (say)

Here, $\lambda$ is a constant, because from left side it would be function of $x$ only or a constant and from right side it would be a function of $y$ only or a constant and both have to be equal in value. And from (6), (7), and (8)

$-\omega^{2} Y(h)+g \frac{d Y}{d y}(h)=0$ $\frac{d Y}{d y}(0)=0$

$\frac{d X}{d x}( \pm l)=0$

From left side of (9)

$\frac{d^{2} X}{d x^{2}}+\lambda^{2} X=0$

$\Rightarrow X(x)=A \cos \lambda x+B \sin \lambda x$

$A$ and $B$ being arbitrary constants, from boundary condition (12)

$\lambda\left[\begin{array}{cc}-\sin \lambda l & \cos \lambda l \\ \sin \lambda l & \cos \lambda l\end{array}\right]\left\{\begin{array}{l}A \\ B\end{array}\right\}=0$

Non-trivial solution of above equation would be,

$-2 \lambda \sin \lambda l \cos \lambda l=0$

This will give two sets of solution in $n \& m$ family as,

$\begin{array}{ll}\lambda_{n}=\frac{n \pi}{l} & ; n=1,2,3, \ldots \ldots, \infty \\ \lambda_{m}=\frac{(2 m+1) \pi}{2 l} & ; m=0,1,2,3, \ldots \ldots, \infty\end{array}$

Thus from (13) and (14), solution of $X(x)$ is,

$\begin{array}{ll}X(x)=A \cos \frac{n \pi x}{l} & ; n=1,2,3, \ldots, \infty \\ X(x)=B \sin \frac{(2 m+1) \pi x}{2 l} & ; m=0,1,2,3, \ldots \ldots, \infty\end{array}$

This is the expression for pattern of standing waves.

Further, from right side of (9)

$\frac{d^{2} Y}{d y^{2}}-\lambda^{2} Y=0$

$\Rightarrow Y(y)=C \cosh \lambda y+D \sinh \lambda y$ 
$C$ and $D$ being arbitrary constants, from boundary condition (11)

$D \lambda=0 \Rightarrow D=0$

From boundary condition (10) and (17)

$-\omega^{2} C \cosh \lambda h+g C \lambda \sinh \lambda h=0$

$\Rightarrow \omega^{2}=g \lambda \tanh \lambda h$

Substituting value of $\lambda$ from (14) in (18), we will get two sets of natural frequencies as,

$\omega_{n}^{2}=\frac{n \pi}{l} g \tanh \frac{n \pi h}{l} \quad ; n=1,2,3, \ldots, \infty$

$\omega_{m}^{2}=\frac{(2 m+1) \pi}{2 l} g \tanh \frac{(2 m+1) \pi h}{2 l} ; m=0,1,2,3, \ldots, \infty$

This expression will give natural frequency of different modes.

\section{EXPERIMENTAL INVESTIGATION}

The setup consists of a rectangular water tank model mounted on shake table. The tank wall is made of thick glass encased inside a steel frame to represent a rigid walled liquid storage tank, as shown in Fig.2. The idea about the tank was taken from manual presented by IISc, Bangalore for earthquake engineering education [12]. The tank was rigidly placed over shake table to represent fixed base and hard soil condition. The table can be excited at different frequencies with different amplitudes. Blue trace was added into the water inside the tank so as to visually observe the waves and maximum sloshing height can be marked on paper, while oscillating at various frequencies.

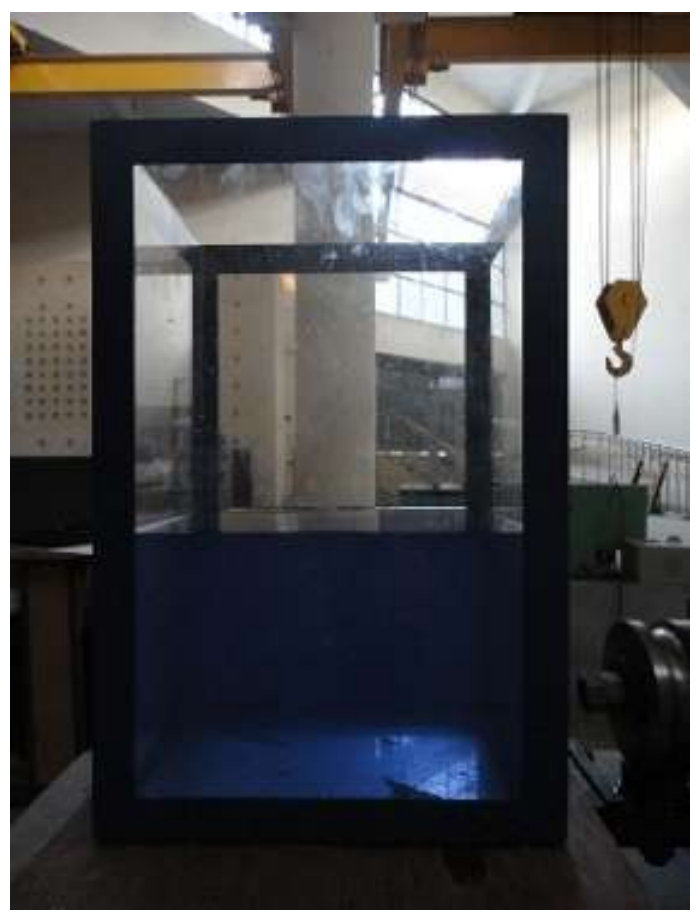

Fig.2- Experimental Model

\section{TEST DATA AND CALCULATIONS}

\subsection{Natural Frequency}

Theoretically, natural frequency is determined by (19), with following data-

$\begin{array}{ll}\text { Length of tank } & L=0.3 \mathrm{~m} \\ \text { Height of water } & h=0.2 \mathrm{~m} \\ & g=9.81 \mathrm{~m} / \mathrm{s}^{2}\end{array} \quad(\therefore l=0.15 \mathrm{~m})$

Where, $\omega$ is in radian. Thus, $f(\mathrm{~Hz})=\frac{\omega}{2 \pi}$

Hence, natural frequency for $n=1,2,3$ and $m=0,1,2,3$ respectively are,

$$
\begin{aligned}
& f_{n l}=2.28 \mathrm{~Hz} \quad \text { and }, \quad f_{m l}=1.59 \mathrm{~Hz} \\
& f_{n 2}=3.23 \mathrm{~Hz} \quad f_{m 2}=2.79 \mathrm{~Hz} \\
& f_{n 3}=3.95 \mathrm{~Hz} \quad f_{m 3}=3.61 \mathrm{~Hz} \\
& f_{m 4}=4.27 \mathrm{~Hz}
\end{aligned}
$$

\subsection{Sloshing Wave Height}

Height of sloshing wave will depend only on convective mode. it is calculated as per recommendations given in IS1893 (Part 1 \& 2) [13], [14] as follows,

(a) Time Period, $T_{c}=C_{c} \sqrt{\frac{L}{g}}$

Where, $C_{c}$ is a function of $h / L$ ratio.

$C_{c}=\frac{2 \pi}{\sqrt{3.16 \tanh (3.16(h / L))}}$

For $h=0.2 \mathrm{~m}, L=0.3 \mathrm{~m}, g=9.81 \mathrm{~m} / \mathrm{s}^{2}$

$\begin{array}{ll} & C_{c}=3.59 \\ \text { Thus, } & T_{c}=0.63 \mathrm{~s}\end{array}$

(b) Design horizontal seismic coefficient

$$
\left(A_{h}\right)_{c}=\frac{Z}{2} \frac{I}{R}\left(\frac{S_{a}}{g}\right)_{c}
$$

Where,

$$
\begin{array}{ll}
Z=0.36 & \text { (for zone-V) } \\
I=1.5 & \text { (for post earthquake importance) } \\
R=2.0 & \text { (for fixed base tank) } \\
T_{c}=0.63 \mathrm{~s} &
\end{array}
$$

Soil condition- Hard

Damping $=0.5 \% \quad$ (for convective mode)

$\therefore$ Multiplying Factor $=2.75$

Thus,

$$
\left(\frac{S_{a}}{g}\right)_{c}=\frac{1}{T_{c}} \times 2.75=4.37
$$

And,

$$
\left(A_{h}\right)_{c}=0.59
$$

(c) Maximum Sloshing Wave Height

$$
d_{\max }=\left(A_{h}\right)_{c} R \frac{L}{2}=0.177 \mathrm{~m} \quad(\text { or } 17.7 \mathrm{~cm})
$$




\section{RESULTS AND DISCUSSION}

\subsection{Natural Frequency}

Variation of natural frequency of different modes with height is shown below in Fig.3, which is obtained from expression (19)
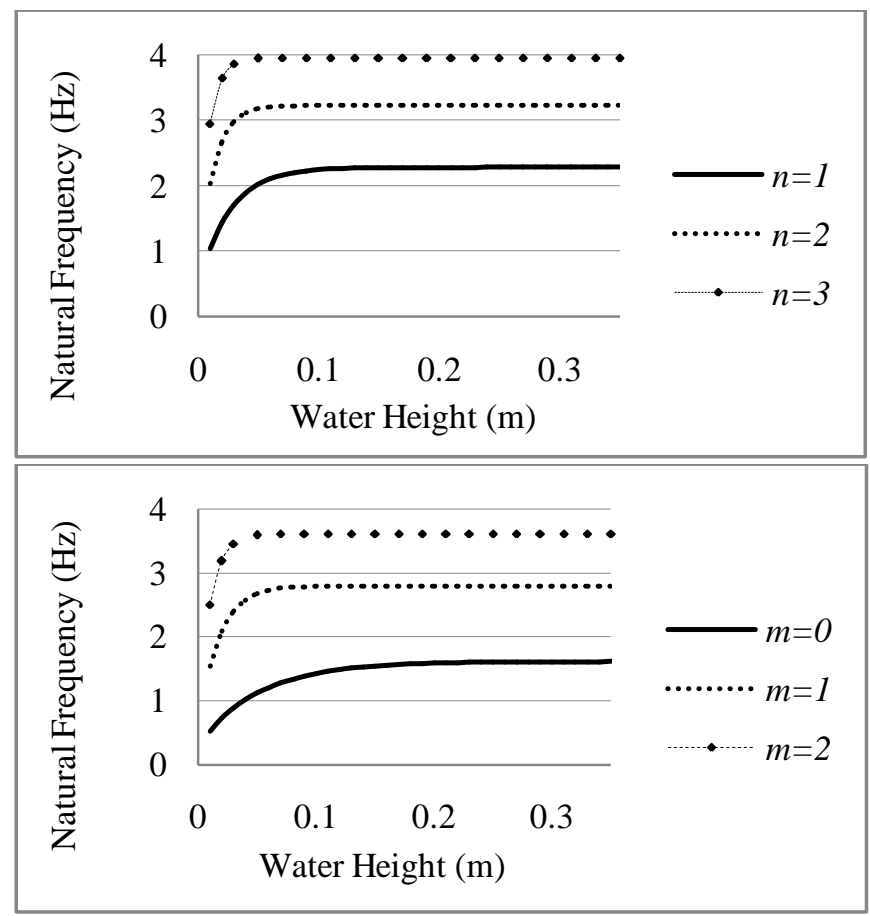

Fig.3 (a) \& (b)- Natural Frequency

\subsection{Theoretical Wave Pattern}

Using expression (15) we can obtain a representative pattern of the induced waves, which is shown below in Fig.4.

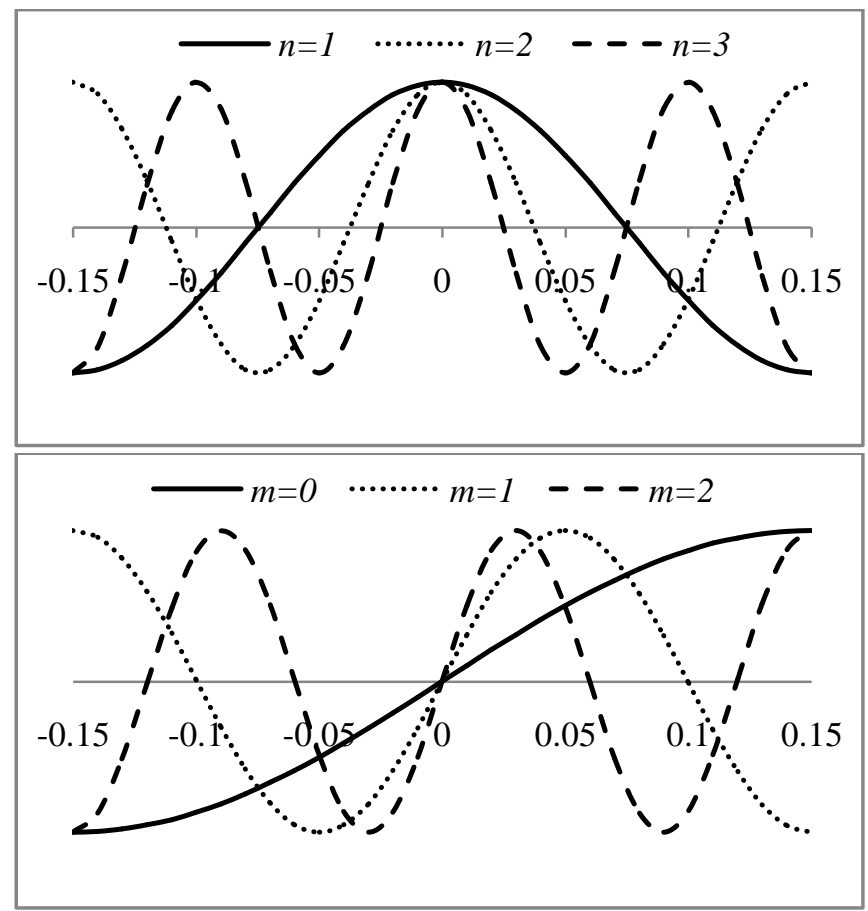

Fig.4 (a) \& (b)- Standing Wave Patterns

\subsection{Experimental Results}

The pattern of induced waves and their trace mark are shown below in figure. Trace mark represents sloshing height of the wave which is indicated in the figures. Fig.5 represents the condition when exciting force is being applied but no resonance is taking place (say, at frequency $1.7 \mathrm{~Hz}$ ). Others Fig.6-9 shows (a) wave pattern, and (b) trace mark while guiding with natural frequencies at mode $1,2,3$, and 4 respectively.

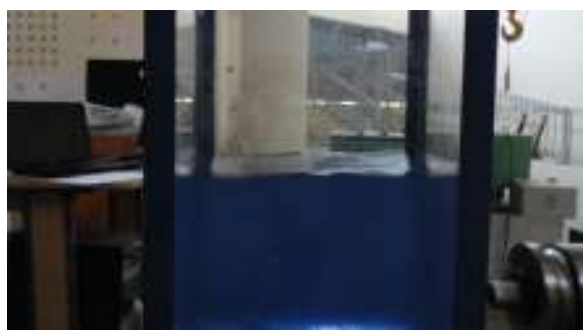

Fig.5- No Resonance Condition

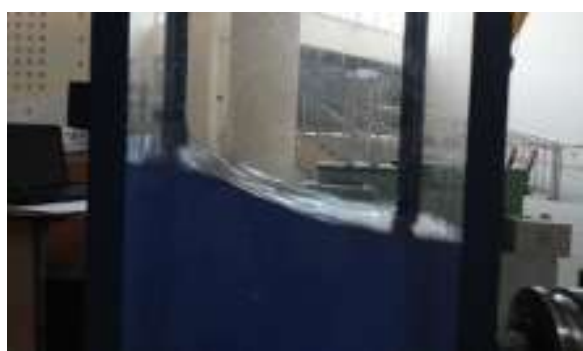

(a)

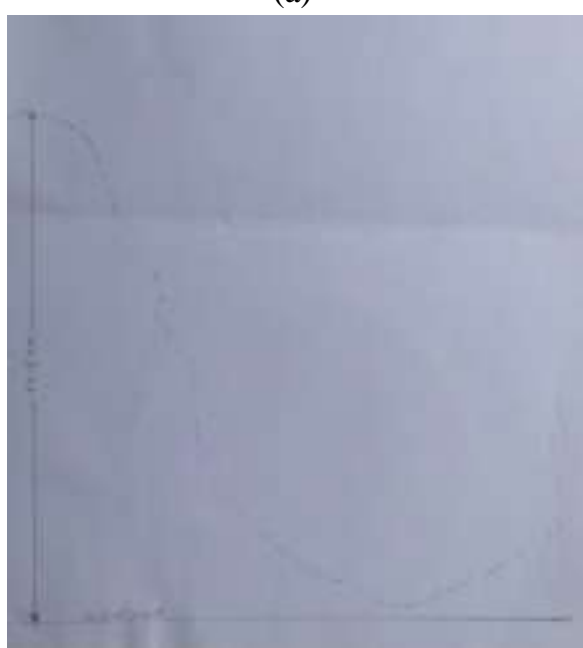

(b)

Fig.6- Mode $1(1.6 \mathrm{~Hz})$

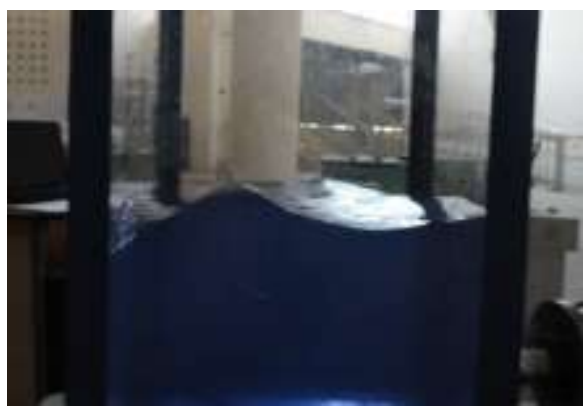

(a) 


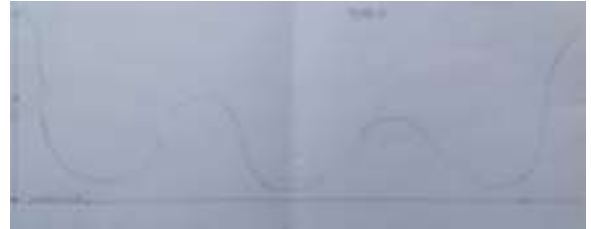

(b)

Fig.7- Mode $2(2.8 \mathrm{~Hz})$

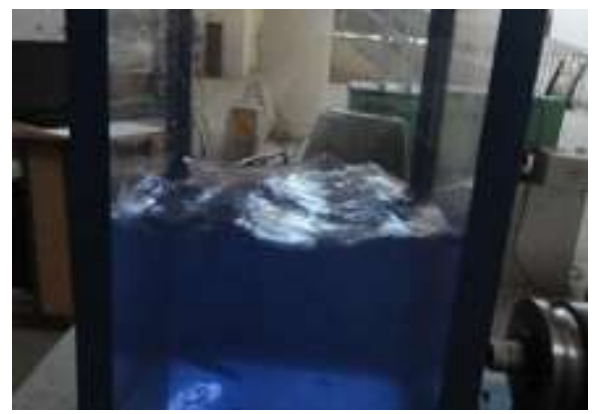

(a)

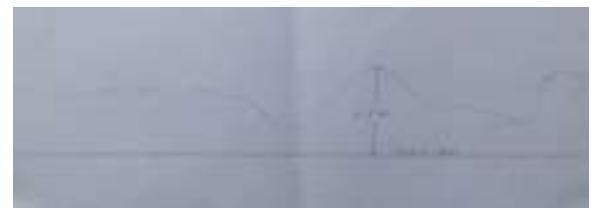

(b)

Fig.8- Mode $3(3.7 \mathrm{~Hz})$

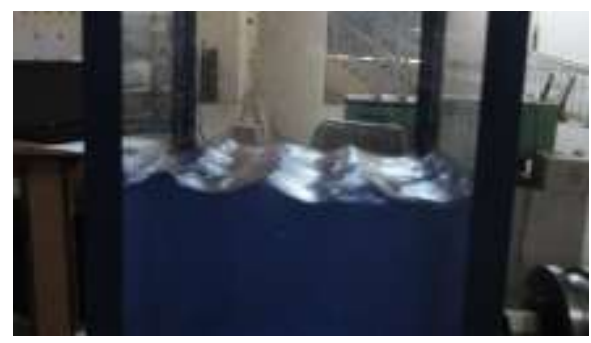

(a)

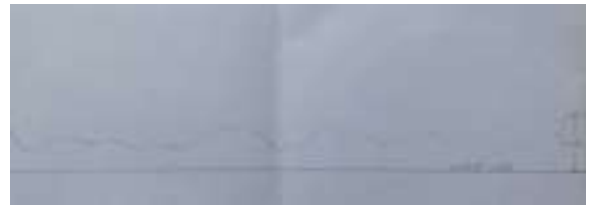

(b)

Fig.9- Mode $4(4.4 \mathrm{~Hz})$

Variation of sloshing wave height with different modes can be observed by bar chart, as shown in Fig. 10.

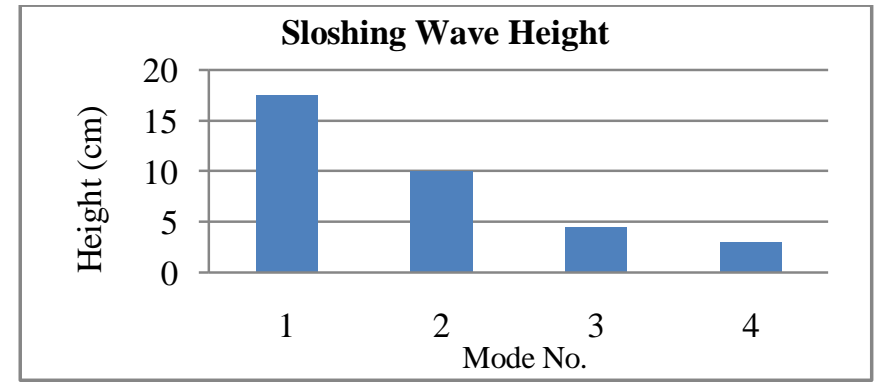

Fig.10- Sloshing Wave Height
For a comparative analysis of results, natural frequencies and sloshing wave heights obtained from experiment and theories are listed below in Table.1.

Table.1- Comparative Results

\begin{tabular}{|c|c|c|c|c|}
\hline \multirow{2}{*}{$\begin{array}{c}\text { Mode } \\
\text { No. }\end{array}$} & \multicolumn{2}{|c|}{ Experimental Result } & \multicolumn{2}{c|}{ Theoretical Result } \\
\cline { 2 - 5 } & $\begin{array}{c}\text { Natural } \\
(\mathrm{Hz})\end{array}$ & $\begin{array}{c}\text { Sloshing } \\
\text { Wave } \\
\text { Height } \\
(\mathrm{cm})\end{array}$ & $\begin{array}{c}\text { Natural } \\
\text { Frequency } \\
(\mathrm{Hz})\end{array}$ & $\begin{array}{c}\text { Sloshing } \\
\text { Wave } \\
\text { Height } \\
(\mathrm{cm})\end{array}$ \\
\hline 1 & 1.6 & 17.5 & 1.59 & 17.7 \\
\hline 2 & 2.8 & 10.0 & 2.79 & - \\
\hline 3 & 3.7 & 4.5 & 3.61 & - \\
\hline 4 & 4.4 & 3.0 & 4.27 & - \\
\hline
\end{tabular}

\section{CONCLUSIONS}

It can be easily observed that after a certain height of water the natural frequency becomes almost independent of the height of water. This is the case of convective frequency. Thus convective time period also becomes independent after a certain value which is justified by looking the variation of $C_{c}$ with $h / L$ ratio in Figure-7 of IS-1893 (Part-2). The natural frequencies getting experimentally and analytically have negligible variation in lower modes but increasing in higher modes. To account for this situation, IS codes recommends a cutoff frequency which is $33 \mathrm{~Hz}$ in IS-1893 (Part-1) and $42 \mathrm{~Hz}$ in Eurocode 8.

Height of sloshing wave is decreasing with increasing mode number. It should also be observed that the sloshing wave height rises only at natural frequencies. In other frequencies disturbance in water surface occurs but without any significant rise. The sloshing wave height calculated from IS code is almost equal to experimental value. The mathematical model gives a good idea of natural frequency and standing wave patterns. Experimental results are in match with one family of mathematical expression.

\section{REFERENCES}

[1] J. R. Cho, J. M. Song, and J. K. Lee, "Finite element techniques for the free-vibration and seismic analysis of liquid-storage tanks," Finite Elem. Anal. Des., vol. 37, no. 6-7, pp. 467-483, 2001.

[2] R. O. Ruiz, D. Lopez-Garcia, and A. a. Taflanidis, "An efficient computational procedure for the dynamic analysis of liquid storage tanks," Eng. Struct., vol. 85, pp. 206-218, 2015.

[3] H. E. Estekanchi and M. Alembagheri, "Seismic analysis of steel liquid storage tanks by Endurance Time method," Thin-Walled Struct., vol. 50, no. 1, pp. 14-23, 2012.

[4] A. Maekawa, "Recent advances in seismic response analysis of cylindrical liquid storage tanks," in Earthquake-Resistant Structures - Design, Assessment and Rehabilitation, 2010.

[5] P. K. Malhotra, T. Wenk, and M. Wieland, "Simple 
procedure for seismic analysis of liquid-storage tanks," Struct. Eng. Int. J. Int. Assoc. Bridg. Struct. Eng., vol. 10, no. 3, pp. 197-201, 2000.

[6] P. K. Malhotra, "Sloshing loads in liquid-storage tanks with insufficient freeboard," Earthq. Spectra, vol. 21, no. 4, pp. 1185-1192, 2005.

[7] R. Livaoglu, "Investigation of seismic behavior of fluid-rectangular tank-soil/foundation systems in frequency domain," Soil Dyn. Earthq. Eng., vol. 28, no. 2, pp. 132-146, 2008.

[8] U. Chaduvula, D. Patel, and N. Gopalakrishnan, "Fluid-structure-soil interaction effects on seismic behaviour of elevated water tanks," Procedia Eng., vol. 51, no. NUiCONE 2012, pp. 84-91, 2013.

[9] J. Z. Chen and M. R. Kianoush, "Generalized SDOF system for seismic analysis of concrete rectangular liquid storage tanks," Eng. Struct., vol. 31, no. 10, pp. 2426-2435, 2009.

[10] G. W. Housner, "The dynamic behavior of water tanks," Bull. Seismol. Soc. Amerrica, vol. 53, no. 2, pp. 381-387, 1963.

[11] I. G. Currie, Fundamental Mechanics of Fluids, Third., vol. 1. 2003.

[12] C. S. Manohar and S. Venkatesha, "Development of experimental setups for earthquake engineering education," 2006.

[13] "IITK-GSDMA Guidlines for seismic design of liquid storage tanks," 2007.

[14] Bureau of Indian Standards, IS-1893 (Part 1): 2002 Indian Standard Criteria for Earthquake Resistant Design of Structures, Part 1 General Provisions and Buildings. 2002. 